\section{Evaluation of inflammation by level of Interleukin 4 in exhaled breath condensate in patients affected by bronchial asthma treated according to GINA guidelines}

\author{
Giuseppe Valerio, Pierluigi Bracciale, \\ Fabio Valerio
}

Divisione di Pneumologia Antonio Blasi, Ospedale Ninetto Melli, Brindisi, Italy

\section{Abstract \\ GINA guidelines suggest that optimal asth-} ma control can be gained by regular monitoring of symptoms, rescue medication use, airways obstruction and variability upon time of airways flows. Our aim was to check if therapy according to GINA rules is able to lower airways inflammation, measured by the level of IL4 in expired breath condensate (EBC). One hundred patients affected by bronchial asthma in different levels were recruited as they come to the ambulatory ward. They were cured according to GINA guidelines for one year, using inhaled fluthicasone as inhaled steroid. Symptoms were monitored by asthma control test score (ACT), airways obstruction by FEV1, bronchial reactivity by PD20, airways inflammation by IL4 in EBC. ACT showed complete control in the first three GINA levels, improving incompletely in the GINA level 4 (from $20 \pm 2$ to $21 \pm 12$; from $17 \pm 2$ to $22 \pm 2$; from $14 \pm 4$ to $18 \pm 3$; from $10 \pm 3$ to $14 \pm 3$ units respectively in the first to fourth levels of asthma). FEV1 improved, but both baseline and after therapy levels were worst in severe persistent asthma (from $96 \pm 5$ to $96 \pm 4$; from $92 \pm 6$ to $93 \pm 3$; from $74 \pm 6$ to $83 \pm 8$; from $45 \pm 10$ to $60 \pm 5 \%$ of normal standards respectively from the $1^{\text {st }}$ to $4^{\text {th }}$ level). PD20 and IL 4 were fairly normalized by therapy in the $s$ and third levels, improved in the last one (PD20 from $437 \pm 329$ to $460 \pm 269$, from $364 \pm 308$ to $>1600$, from $436 \pm 252$ to $890 \pm 220$; from $45 \pm 25$ to $60 \pm 40 \mathrm{mcg}$ respectively, IL4 in EBC from $60 \pm 6$ to $40 \pm 12$, from $65 \pm 10$ to $41 \pm 9$, from $72 \pm 8$ to $45 \pm 6$, from $78 \pm 20$ to $52 \pm 5$ respectively). IL4 and PD20 were significantly related. Experimental data allowed the assessment of the correlation of inflammation with bronchial reactivity and the relevance of addressing therapy upon IL4. Severe persistent asthma behave as a different entity with worst baseline inflammation, partially refractory asthma and persistent inflammation, needing specific immunologic weapons. Bronchial inflammation was fairly reduced but not normalized after one year of therapy.

\section{Introduction}

In the therapy of bronchial asthma (BA), current GINA guidelines ${ }^{1}$ assign a specific level of gravity according to symptoms, airways obstruction and peak flow (PEF) variability. GINA levels suggest the appropriate intensity of therapy necessary for the treatment to achieve good asthma control. Thereafter changes of therapy depends on routine followup and reassessment to determine if a patient is well-controlled, partly controlled or uncontrolled. BA is characterized by persistent inflammation, reversible obstruction, and bronchial hyper-reactivity, ${ }^{1-3}$ weakly related with symptoms FEV1 and PEF variability .

Improvement of knowledge about underlying inflammation can be obtained using the bronchial hyper reactivity as a monitor. ${ }^{4,5}$ However, the goals of therapy would be better achieved by addressing the therapy using a direct marker of bronchial inflammation.

Within allergic inflammation IL4 is an appropriate marker since it plays a major role in priming naive $\mathrm{T} 0$ lymphocytes to Th2 with activation of the cascade IL4, IL5, IL9, IL13, ${ }^{2,6}$ while IL5 is mainly responsible of eosinophils recruitment and both IL9 and IL13 for bronchial hyperreactivity. The less invasive, most reproducible and most effective way to measure bronchial inflammation is to perform the dosage of IL4 in Expired Breath Condensate (EBC), as already shown in other studies. $3,7-10$

Our aim is to assess if long term therapy, conducted according GINA guidelines in compliant BA patients of different severity is able to lower and normalize bronchial inflammation assessed by means of IL4 in EBC.

\section{Materials and Methods}

One hundred non smoking caucasian patients which never smoked but were affected by allergic bronchial asthma, according to GINA guidelins, were enrolled as they were consecutively refered to the outpatient clinic of the respiratory disease division. They were symptom free without bronchial airways infection in the previous month. Informed consent was obtained. Compliance and motivation were obtained through effective information and periodic calls and it was checked by careful observation of drug consumption (weighting the canisters and counting the prescriptions). Only patients compliant to the assigned therapy were studied. A group of 20 healthy subjects were submitted to the same procedures as control group. For ethical reasons it was not possible to compare the results to a set of patients kept without therapy for one year.
Correspondence: Giuseppe Valerio, Divisione di Pneumologia Antonio Blasi, Ospedale Ninetto Melli, via Lecce 24672027 San Pietro V.co, Brindisi, Italy.

Tel. +39.0831528560 - Fax: +39.0831 .520258 .

E-mail valeriospinosa@libero.it

Key words: bronchial asthma, Il4 , GINA , expired breath condensate, bronchial hyperreactivity, EBC, TD20.

Contributions: the authors contributed equally.

Conflict of interest: the authors report no conflicts of interest and received no grant.

Received for publication: 15 March 2011

Revision received: 25 August 2011.

Accepted for publication: 5 September 2011.

This work is licensed under a Creative Commons Attribution NonCommercial 3.0 License (CC BYNC 3.0).

(C) Copyright G. Valerio et al., 2011

Licensee PAGEPress, Italy

Chest Disease Reports 2011; 1:e11

doi:10.4081/cdr.2011.e11

After the assessment of allergy by prick tests and IgE level, a wash out period lasting one month was allowed, to avoid the effects of previous drugs, treating the airways obstruction by salbutamol inhalation only at needing. Symptoms control, airways obstruction, degree of airways reactivity, level of IL4 in EBC were assessed and the patient was assigned to a specific GINA level. Therapy was administered according to GINA rules and the measurements were repeated after one year of therapy. During the period of therapy, evaluation of adherence to therapy was determined by periodic visits and detailed information. Patients affected by bronchial intermittent asthma were treated by inhalation of salbutamol spray as needed. Patients with persistent asthma were treated by fluthicasone propionatae (FP) and salmeterol (25 mg+250 umg twice/day). In case of moderate asthma, montelukast (10 $\mathrm{mg}$ /day) was assigned in addition; theophylline (20 0mgx2/day) was prescribed only as needed. In the last step zarfilukast (20 mgx2/day) plus salmeterol-fluticasone (25 mg+250 mcg twice a day) association, theophylline and prednisolone (5 $\mathrm{mg} /$ day) were used (Table 1). Within one year some patients experienced seasonal relapses due to allergenic load and were treated according to GINA guidelines. During measurement they were free of seasonal allergen load.

The Asthma Control Test (ACT) was administered according to literature ${ }^{11,12}$ to check for the control of symptoms. Skin prick tests were performed (according the EAACI suggestion) by a panel of allergen extracts (ALK-Abello, 
Spain) responsible for allergy in the Mediterranean regions, measuring wheal flare after fifteen min in the forearm. The diameter was compared to saline, as negative control, and histamine, as a positive control. A positive reaction was considered by the presence of one or more wheal flares larger than $5 \mathrm{~mm}$. Circulating IgE was dosed by immunocolorimetric method (Beckman, USA).

Forced expired vital capacity (FVC),forced expired volume in one s (FEV1), Peak expiratory flow rate (PEFR) were measured by turbine spirometer (MIR, Italy) and the data were referred to ERS normal standards. Bronchial Provocation Test (BPT) was conducted according to the stepwise cumulative inhalation of buffered methacholine chloride (Mefar dosimeter, Brescia, Italy) to trace a semi logarithmic plot of FEV1 deflection against the cumulative inhaled dose. PD20 was assumed as the provocative dose causing $20 \%$ decrease of FEV1, interpolated from the relation between natural logarithm of the dose and percentage of fall of FEV1. The test was conducted according the ERS standards.

Exhaled breath condensate was collected by a condenser (Ecoscreen, Jaeger, Hoechberg, Germany), while patients breathed for ten min, using a nose clip at normal breathing rate and tidal volume through a two way non re breathing valve. A saliva trap was put in the expiration line and the dosage of amylase allowed the exclusion of samples with mouth secretion contamination. The volume of the condensate (average 2cc) was collected in a plastic tube and kept at a $-70^{\circ} \mathrm{C}$ in Eppendorf tubes. The dosages were examined within three months from collection. A double sand- wich enzymatic immunoassay test was used to measure IL4 (EIA), (Cayman Chemical, Ann Arbor, MI, USA). The intra-assay variability was within $10 \%$. The dosages were repeated twice and the measured coefficient of variation was $5 \%$.

Data were expressed as mean \pm standard deviation. The comparison of means was conducted by means of T-test by statistical package (Epistat, Richardson,Texas, USA). Least square method analysis allowed the analysis of regressions between variables. Differences are reported as significant for a level of probability (P) less than .05 and highly significant if less than .001 . The study was approved by the Ethic Committee of Ninetto Melli Hospital .Written informed consent was obtained from all patients. The paper was approved by the Institutional Review Board (IRB).

\section{Results}

The majority of the 100 patients referred for asthma care to our clinic were found to be GINA levels 1-3. The average age of patients increased in the consecutive steps from 28 years in the first level to 52 years in severe persistent asthma. Biometry was similar. Forced Vital Capacity (FVC) was significantly lower in severe persistent asthma. Airways obstruction (FEV1) was significantly impaired on mild and severe persistent asthma. Atopy, assessed by IgE and blood eosinophils, showed the highest values in severe persistent asthma.

ACT scores decreased in the successive levels; moderate persistent and severe persistent asthma scores were significantly lower than under intermittent. After therapy ACT scores showed a fairly constant and significant increase in each level, but the difference between severe persistent and the other levels was still significant (from $20 \pm 2$ to $21 \pm 12$; from $17 \pm 2$ to $22 \pm 2$; from $14 \pm 4$ to $18 \pm 3$; from $10 \pm 3$ to $14 \pm 3$ units respectively in the first to fourth levels of asthma). After therapy the control of symptoms (ACT) was almost completely achieved in the first two levels of severity, quite satisfactory in the third one and improved but not completely controlled in the last one.

Airways bronchial obstruction (FEV1) was significantly worse in moderate and severe persistent asthma before therapy. The treatment significantly increased FEV1 in severe persistent asthma. The comparison within the different levels after therapy showed a persistent airways obstruction in severe persistent asthma (from $96 \pm 5 \%$ to $96 \pm 4 \%$; from $92 \pm 6 \%$ to $93 \pm 3 \%$; from $74 \pm 6$ to $83 \pm 8 \%$; from $45 \pm 10 \%$ to $60 \pm 5 \%$ of normal standards respectively from the $1^{\text {st }}$ to the $4^{\text {th }}$ level). Airways obstruction (FEV1) improved in persistent asthma, but the difference between severe persistent and the other levels was still significant.

The bronchial hyperreactivity (PD20) showed a significant difference between each level, worsening progressively. Therapy did not improve PD20 in the first level, but significantly improved in the other three consecutive levels, although the PD20 still remained significantly lower in severe persistent asthma (PD20 from $437 \pm 329$ to $460 \pm 269$, from $364 \pm 308$ to $>1600$, from $436 \pm 252$ to $890 \pm 220$;

Table 1. Features of patients and therapy used.

\begin{tabular}{|c|c|c|c|c|c|c|}
\hline & $\begin{array}{l}\text { Healthy } \\
\text { controls }\end{array}$ & Intermittent & $\begin{array}{l}\text { Mild } \\
\text { persistent }\end{array}$ & $\begin{array}{l}\text { Moderate } \\
\text { persistent }\end{array}$ & $\begin{array}{l}\text { Severe } \\
\text { persistent }\end{array}$ & Units \\
\hline Age & $35 \pm 15$ & $28 \pm 13$ & $35 \pm 15$ & $41 \pm 15$ & $52 \pm 14$ & Years old \\
\hline Gender & $10: 10$ & 11:12 & $20: 20$ & $9: 12$ & $7: 9$ & $\mathrm{M}: \mathrm{F}$ \\
\hline Height & $168 \pm 5$ & $170 \pm 5$ & $170 \pm 7$ & $168 \pm 5$ & $165 \pm 6$ & $\mathrm{Cm}$ \\
\hline BMI & $26 \pm 7$ & $25 \pm 6$ & $28 \pm 7$ & $24 \pm 5$ & $24 \pm 4$ & $\mathrm{Cm}^{2} / \mathrm{kg}$ \\
\hline FVC & $110 \pm 7$ & $98 \pm 2$ & $97 \pm 2$ & $85 \pm 4$ & $75 \pm 10$ & \%pred \pm sd \\
\hline FEV1 & $105 \pm 4$ & $96 \pm 5$ & $92 \pm 6$ & $74 \pm 6$ & $45 \pm 10$ & $\%$ pred \pm sd \\
\hline $\operatorname{Ig} \mathrm{E}$ & $70 \pm 30$ & $389 \pm 510$ & $254 \pm 300$ & $291 \pm 400$ & $419 \pm 475$ & $\mathrm{U} / \mathrm{lt}$ \\
\hline Eos & $120 \pm 25$ & $372 \pm 194$ & $325 \pm 208$ & $352 \pm 224$ & $415 \pm 442$ & Cell/cc \\
\hline Salbut. rescue & $40 \pm 10$ & & & $20 \pm 20$ & $40 \pm 20$ & Mg/day \\
\hline Salmeterol & & & 50 & 50 & 50 & Mg/day \\
\hline Fluticasone & & & 250 & 500 & 500 & Mcg/day \\
\hline Montelukast & & & & 10 & & Mg/day \\
\hline Zarfilukast & & & & & 60 & Mg/day \\
\hline Theophylline & & & & $400 \pm 100$ & $400 \pm 100$ & Mg/day \\
\hline Prednisolone & & & & & $7 \pm 7$ & Mg/day \\
\hline N. & 20 & 23 & 40 & 21 & 16 & $\mathrm{~N}$ \\
\hline
\end{tabular}

BMI, body mass index; FVC, forced vital capacity; FEVl, forced exp. volume in one s; Eos, circulating eosinophils/cc; Salbut. rescue, dose of salbutamol inhaled to resume bronchospasm. 
from $45 \pm 25$ to $60 \pm 40 \mathrm{mcg}$ respectively). IL4 in EBC was significantly increased in severe persistent asthma (IL4 in EBC from $60 \pm 6$ to $40 \pm 12$, from $65 \pm 10$ to $41 \pm 9$, from $72 \pm 8$ to $45 \pm 6$, from $78 \pm 20$ to $52 \pm 5 \mathrm{pg} / \mathrm{mL}$ respectively). Allergic inflammation, according to IL4 levels, is fairly reduced in the first three levels, but it was still active in the level four. Allergic inflammation and bronchial hyper reactivity showed a reciprocal trend.

\section{Discussion}

The current study demonstrated that conventional therapy conducted according to GINA guidelines in compliant patients is able to control bronchial inflammation in the first three asthma levels with a trend toward normalization. The last level requires additional therapeutic weapons.

Several investigative tools have been proposed for the assessment of the degree of inflammation in bronchial asthma such as the levels of Nitric Oxide (NO) and Carbon Monoxide (CO) in the expired gas, the examination of induced sputum (IS) for assay of interleukins and mediators as well as the count of eosinophils, the examination of Broncho- Alveolar Lavage (BAL) and bronchial biopsy. We disagree with the use of IS since the inhalation of hypertonic solutions for induction of secretions determines bronchospasm; expired gas analysis seems almost limited, while EBC looks suitable because it is well tolerated and easily reproducible, despite technological problems, currently under standardization and solution. ${ }^{13}$

Within the different monitors of inflammation we chose IL 4 because it plays a pivotal role in the allergic response. It determines the prevalence of allergy through the genic polimor- physm $^{14}$ and through the ratio between the ILA receptor (active upon the cells surface) and the soluble IL4 receptor (inefficient). IL4 regulates an immunologic network influencing mastocytes function (increasing IgE affinity), B lymphocytes (decreasing (?) IgE affinity), T lymphocytes (priming T0 into Th2 ), fibroblasts (it regulates the secretion of pro-collagen I) and endothelial cells (up-regulation of vascular cell adhesion molecule-1 (VCAM-1)., ${ }^{2,3,6,14-20}$ It is over expressed in the bronchial biopsy in patients affected by asthma and allergic rhinitis and in the blood during the acute phase and after bronchial provocation, while it is reduced during therapy. ${ }^{3,20}$ The current experience aims to assess whether the effect of therapy, conducted according to GINA guidelines, using FP as ICS, upon a long time span and in all levels of asthma, is able to lower airways inflammation. According to our results, the first three levels of asthma are under satisfactory control, adopting GINA guidelines: both symptoms and bronchial hyper reactivity and allergic inflammation are significantly reduced by therapy in GINA levels 2 and 3 , with a fair concordance with literature data, ${ }^{21}$ confirming as well the significant relationship between inflammation (ILA) and hyper reactivity (PD20). ${ }^{3}$

Results are in full agreement with previous experience of levels of IL4 in EBC infant asth$\mathrm{ma}^{22}$ and in moderate persistent asthma in adults, ${ }^{3}$ showing raised baseline values of ILA and $\mathrm{pH}$ in EBC with a diminution after a six months lasting period of FP therapy despite normalization of the symptoms and airways hyper reactivity. The current data were obtained after a longer time span and indicate that therapy did not reduce inflammation and bronchial hyper reactivity in GINA level 1, because ICS were not prescribed, raising the question concerning the opportunity to prescribe inhaled ICS in first level as well. In persistent asthma both six months lasting ${ }^{3}$ and twelve months lasting (Table 2) therapy were not sufficient to stop bronchial inflammation, indicating the need of a longer time of therapy. The therapy of severe persistent asthma is not complete, despite the addition of oral steroids. Severe persistent asthma behaves as a peculiar disease partially refractory to therapy because of persistent bronchial inflammation leading to structural damages and remodelling. ${ }^{23,24}$

The practical implication is that ILA levels indicate the need for therapies longer than those suggested by the trends of symptoms or hyperreactivity BHR, since bronchial inflammation is reduced after long term therapy, but not back to normal levels. Severe persistent asthma behaves as a refractory disease, possibly needing a more aggressive therapy.

\section{Conclusions}

The therapy conducted according to GINA guidelines, over one year lasting time span, allows reducing bronchial inflammation in mild and moderate levels. The diminution of inflammation is related to the improvement of bronchial hyperreactivity. After one year of therapy the inflammation is not completely overcome and it is necessary to avoid loss of adherence to the therapy, due to disappearance of symptoms, possibly leading to early withdrawal and relapse of the disease. Severe persistent asthma behave as a different entity with the higher baseline inflammation, raised IL4 levels, marked bronchial hyperreactivity, limited improvement after therapy according to GINA guidelines, requesting a precise identification of the phenotype of asthma and the use of more complex and specific weapons to reduce airways inflammation such as anti IgE antibodies.

Table 2. Effect of therapy lasting twelve months in asthmatic patients.

\begin{tabular}{|c|c|c|c|c|c|c|}
\hline & $\begin{array}{l}\text { Healthy } \\
\text { controls }\end{array}$ & Intermittent & $\begin{array}{c}\text { Mild } \\
\text { persistent }\end{array}$ & $\begin{array}{l}\text { Moderate } \\
\text { persistent }\end{array}$ & $\begin{array}{c}\text { Severe } \\
\text { persistent }\end{array}$ & Units \\
\hline ACT & $23 \pm 2$ & $20 \pm 2$ & $17 \pm 2$ & $14 \pm 4$ & $10 \pm 3$ & $\mathrm{U}$ \\
\hline ACT th & $22 \pm 2$ & $21 \pm 2$ & $22 \pm 2$ & $18 \pm 3$ & $14 \pm 3$ & U \\
\hline $\mathrm{P}$ & n.s. & n.s. & $*$ & $\circ$ & $*$ & \\
\hline FEV1 & $113 \pm 12$ & $96 \pm 5$ & $92 \pm 6$ & $74 \pm 6$ & $45 \pm 10$ & \%pred \pm sd \\
\hline FEV1 th & $110 \pm 15$ & $96 \pm 4$ & $93 \pm 3$ & $83 \pm 8$ & $60 \pm 5$ & $\%$ pred \pm sd \\
\hline $\mathrm{P}$ & n.s. & n.s. & n.s. & n.s. & $*$ & \\
\hline PD20 & $>1600$ & $437 \pm 329$ & $364 \pm 308$ & $436 \pm 252$ & $45 \pm 25$ & Mcg \\
\hline PD20 th & $>1600$ & $460 \pm 269$ & $>1600$ & $890 \pm 220$ & $60 \pm 40$ & Mcg \\
\hline $\mathrm{P}$ & n.s. & n.s. & $\circ$ & $\circ$ & n.s. & \\
\hline IL4EBC & $30 \pm 15$ & $60 \pm 6$ & $65 \pm 10$ & $72 \pm 8$ & $78 \pm 20$ & $\mathrm{pg} / \mathrm{mL}$ \\
\hline IL4EBCth & $33 \pm 13$ & $60 \pm 12$ & $41 \pm 9$ & $45 \pm 6$ & $52 \pm 5$ & $\mathrm{pg} / \mathrm{mL}$ \\
\hline $\mathrm{P}$ & n.s. & n.s. & ${ }^{\circ}+$ & $\circ$ & $\circ$ & \\
\hline
\end{tabular}


gastro-esophageal reflux and gastroesophageal refllux related asthma. J Int Med 2006:259:323-31.

1. National Heart, Lung and Blood Institute, National Institutes of Health. Global initiative for asthma. Global strategy for asthma management and prevention. Udated from: NHLBI/WHO Workshop Report Issued January, 1995. Bethesda, MD. US Department of Health and Human Services: NIH Publication, No. 02-3659; 2003.

2. Tsoumakidou N, Tzanakis N, Kyriaakou D, et al. Inflammatory cell profiles and T lymphocyte subsets in COPD and severe persistent asthma. Clin Exp Allergy 2004;34: 234-40.

3. Carpagnano GE, Foschino Barbaro MP, Resta 0, et al. Exhaled markers in the monitoring of airways inflammation and its response to steroids's treatment in mild persistent asthma. Eur J Pharmacol 2005; 519:175-81.

4. Sont JK, Willems LN, Sterk PJ, et al. Clinical control and histopathologic outcome of asthma when using airway hyperresponsiveness as an additional guide to long term treatment. The AMPUL Study Group. Am J respire Critic Care Med 1999;159: 1043-51.

5. Nuijsink M, Hop WC, Sterk PJ, et al. Long term asthma treatment guided by airway hyperresponsiveness in children: a randomised controlled trial. Eur Respir J 2007;30:457-66.

6. Tosca MA, Cosentino C, Pallestrini E, et al. Medical treatment reverses cytokine pattern in allergic and nonallergic chronic rhinosinusitis in asthmatic children. Pediatr Allergy Immunol 2003;14:238-41.

7. Carpagnano GE, Resta 0, Ventura MT, et al. Airway inflammation in subjects with
8. Matsunaga K,Yanagisawa S, Ichikawa T, et al. Airway cytokine expression measured by means of protein array in exhaled breath condensate: correlation with physiologic properties in asthmatic patients. $\mathrm{J}$

9. 0'Byrne PM. Cytokines or their antagonists for the treatment of asthma. Chest 2006;130:244-50.

10. Simpson JL, Wood LG, Gibson PG. Inflammatory mediators in exhaled breath, induced sputum and saliva. Clin Exp Allergy 2005;35:1180-5.

11. Nathan RA, Sorkness CA, Kosinski M, et al. Development of the asthma control test: A survey for assessing asthma control. J Allergy Clin Immunol 2004;113:59-65.

12. Bateman ED, Boushey HA, Bousquet J, et al. Can guideline-defined asthma control be achieved? The Gaining Optimal Asthma Control Study. Am J Resp Crit Care Med 2004;170:836-44.

13. Borril ZL, Roy K, Singh D. Exhaled breath condensate biomarkers in COPD. Eur Respir J 2008;32;472-86.

14. Isidoro-Garcia M, Davila I, Laffond $\mathrm{E}$, et al. Interleukin-4 (IL4) and Interleukin-4 receptor (Il4RA) polymorphism in asthma: a case control study. Clin Mol Allergy $2005 ; 29 ; 3: 15$.

15. Beghè $B$, Barton $S$, Rotke $S$, et al. Polymorphisms in the interleukin-4 and interleukin-4 receptor alpha chain genes confer suscepètibility to asthma and atopy an a Caucasian population. Clin Exp Allergy 2003;33:1111-7.

16. Plante S, Semiali A, Joubert P, et al. Mast cell regulate procollagen I (alpha 1) production by bronchial fibroblasts derived Allergy Clin Immunol 2006;118:84-90. from subjects with asthma through IL-4/IL4 delta 2 ratio. J Allergy Clin Immunol 2006;117:1321-7.

17. Stanklievitz W, Dabrowski MP, Chcialowski A, Plusa T. Cellular and cytokine immunoregulation in patients with COPD and bronchial asthma. Mediators Inflamm 2002;11:307-12.

18. Webb DC, Mc Kenzie AN. Integrated signals between IL-13, IL-14 and IL-15 regulate airways hyppereactivity. J Immunol 2000;165:108-13.

19. Woodroff PG, Khasheyr R, Fahji V. Relationship between hyperresponsiveness and obstruction in asthma. J Allergy Clin Immunol 2001;108:753-8.

20. Choy DK, Ko F, Li ST, et al. Effects of theophylline, dexamethasone and salbutamol on cytokine gene expression in human peripheral blood CD4+ t ceels. Eur Respir J 1999;14:1106-12.

21. Shashid SK, Kharithonov SA, Wilson NM, et al. Increased interleukin 4 and decreased interferon gamma in exhaled breath condensate of children with asthma. Am J Respir Crit Care Med 2002;165: 1290-3.

22. Barnes PJ. Cytokine modulators as novel therapies for airways disease. Eur Repir J Suppl 2001;34:67s-77s.

23. Oga T, Nishimura K, Tsukino $M$, et al. Changes in indices of airway hyperresponsiveness during one year of treatment with inhaled steroids in patients with asthma. $\mathrm{J}$ Asthma 2001;38:133-9.

24. Vrugt B, Wilson S, Underwood J, et al. Mucosal inflammation in severe glucocoticoid dependent asthma. Eur Respir J 1999; 13:1245-52. 